\title{
Microorganisms isolated from cultures and infection focus and antibiotic treatments in febrile neutropenic children from Şanlıurfa, Turkey
}

\author{
Z. Canan Özdemir ${ }^{1}$, Ahmet Koç², Ali Ayçiçek ${ }^{3}$ \\ ${ }^{1}$ Division of Pediatric Hematology, Department of Pediatrics Harran University Faculty of Medicine, Şanluurfa, ${ }^{2}$ Division \\ of Pediatric Hematology/Oncology, Department of Pediatrics, Marmara University Faculty of Medicine, İstanbul, ${ }^{3}$ Eskişshir \\ State Hospital, Eskişehir, Turkey. E-mail:efecanan@yahoo.com \\ Received: 30 October 2014, Revised: 25 November 2014, Accepted: 9 December 2014
}

SUMMARY: Özdemir ZC, Koç A, Ayçiçek A. Microorganisms isolated from cultures and infection focus and antibiotic treatments in febrile neutropenic children from Şanlıurfa, Turkey. Turk J Pediatr 2016; 58: 47-53.

Chemotherapy induced febrile neutropenia predisposes patients to life threatening infections. We aimed to determine the causative microorganisms, infection focus and antibiotic treatment success in febrile neutropenic children with leukemia. A total of 136 febrile neutropenic episodes in 48 leukemic children were reviewed retrospectively from records. Among 136 febrile neutropenic episodes, 68 (50\%) episodes were microbiologically documented. Methicillin sensitive coagulase (-) Staphylococcus aureus were the most common isolates from hemoculture $(20.5 \%)$. The most frequently documented infection focus was mucositis $(31.9 \%)$. Ceftazidime plus amikacin was the most commonly used antimicrobial treatment for the empirical therapy $(52.9 \%)$. The overall response rates were $70.5 \%, 86.9 \%$, and $66.6 \%$ of first line, second line and third line therapies, respectively.

The spectrum of isolates among febrile neutropenic children in our hematology clinic appears to be gram positive pathogens which are the most common agents. Therefore the, documentation of the flora in each unit could help to decide appropriate empirical therapy which is life saving.

Key words: child, leukemia, fever, neutropenia, empiric therapy.

Neutropenia is one of the most common complications in children with cancer, and it is the most important parameter to determine infection risk. In neutropenic patients the signs and symptoms could be scarce and in occasions fever could be the only symptom ${ }^{1}$. Life threatening complications due to bacterial infections have been reported in $3-10 \%$ of all febril neutropenic episodes ${ }^{2}$.

Recent studies have found that $29-60 \%$ of neutropenic patients who become febrile have bacterial infections, of which $16-25 \%$ have bacteremias and gram $(+)$ bacteremia has increased up to $60-70 \%$ of all microroganisms identified $^{3,4}$. Several studies suggest that a causative agent could not be documented in almost two-thirds of infectious episodes ${ }^{5}$. Presumably because immediately administration of empirical therapy masks documentation of infection.
The selection of empirical therapy should be based on a variety of factors such as a patient's infectious risk, potential sites, causative organisms and sensitivity of those organism to antibiotics ${ }^{6}$. In addition, individual centers should aim to describe the epidemiology of bacteremia to guide empiric antibiotic treatment among children with neutropenia. We aimed to determine the infection focus, causative organisms and effeciency of antibiotic treatment in our pediatric hematology clinic.

\section{Material and Methods}

In total, 48 leukemic children admitted to Pediatric Hematology Clinic of Harran University Faculty of Medicine between January 2008- June 2010 were evaluated in this study. Sixteen episodes were excluded from the study. These episodes had no complete clinical and laboratory evaluation. A hundred thirty six 
Table I. Characteristic of Children and Febrile Episodes

\begin{tabular}{lc}
\hline Mean age (year) & $7.20 \pm 3.81(1.5-16.5)$ \\
\hline Mean duration of neutropenia (day) & $7.67 \pm 4.1(2-23)$ \\
Mean number of febrile episodes & $2.56 \pm 1.93(1-11)$ \\
Microbioligically documented infection & $68(50 \%)$ \\
Clinically documented infection & $47(35 \%)$ \\
Fever unknown origin & $21(15 \%)$ \\
\hline
\end{tabular}

febrile episodes were anlaysed retrospectively. Neutropenia was defined as an absolute neutrophil count of $<500$ cells $/ \mathrm{mm}^{3}$ or a count of $<1000$ cells $/ \mathrm{mm}^{3}$ with a predicted decrease to $<500$ cells $/ \mathrm{mm}^{3}$. Fever was defined as a single tympanic temperature $\geq 38.3{ }^{\circ} \mathrm{C}$ or a temperature of $\geq 38^{\circ} \mathrm{C}$ at least 1 hour ${ }^{7}$. A blood culture was considered to be contaminated if coagulase-negative staphylococci, micrococcus species, corynebacterium species in a single bottle and were excluded from this analysis. Patients were included more than once in the analysis for separate episodes of bacteremia ${ }^{8}$. A urine culture was considered contaminated when it had a bacterial count greater than 100,000 colonies $/ \mathrm{ml}^{9}$.

Febrile noeutropenic episodes were classified as fever of unknown origin (FUO), clinically or microbiolgically documented infection. FUO was defined as fever without any focus or etiology identified by clinical history, physical examination, radiological or microbiologic testing ${ }^{10}$. The diagnosis of microbiologically documented infection was based on both isolation and a causative organism from body fluids. Clinically documented infection was defined as there was evidence of focal inflammation on physical examination but without microbiological confirmation ${ }^{11}$.
The first line antibiotic (empirical) treatments were started at the beginning of fever period in all children. First line antibiotic treatment included; cefepim or ceftazidime alone, cefepim, ceftazidime or cefaperazon-sulbactam with amikacin or carbapenem alone. If the fever persist after $\geq 48-72$ hours of empirical treatment, or children had gram $(+)$ bacteria isolated from hemoculture, glycopepetid was started as a second line treatment. After 4-5 days, if fever did not settle then either glycopeptid was added or if there was suspicion of fungal infection, antifungal therapy was started as a third line therapy.

\section{Results}

A total of 136 episodes were documented in 48 leukemic children. Forty children with acute lymphoblastic leukemia (83.3\%), 8 children with acute myeloblastic leukemeia (16.7\%). There were 27 males (56.3\%) and 21 females (43.8\%) whose age ranged from 1.5-16.5 years (mean age $7.2 \pm 3.81$ ). The episodes were classified as such: 68 (50\%) of febrile episodes were documented microbiologically, 47 (35\%) episode were clinically documented infections and $21(15 \%)$ episodes were classified as FUO. Characteristics of children and febrile episodes are summarized in Table I.

Table II. Clinically Documented Infection Focus of Febrile Episodes

\begin{tabular}{|c|c|c|}
\hline Infection focus & $\mathrm{n}$ & $\%$ \\
\hline Oral mucositis & 15 & 31.9 \\
\hline Upper respiratory tract ${ }^{*}$ & 14 & 29.7 \\
\hline Pneumonia & 5 & 10.6 \\
\hline Enterocolitis & 5 & 10.6 \\
\hline Soft tissue & 4 & 8.5 \\
\hline Labial herpes & 4 & 8.5 \\
\hline Total & 47 & 35 \\
\hline
\end{tabular}

"Otitis media, sinüsitis, tonsillitis, pharyngitis 
Clinical infection focus was documented in 47 (35\%) of febrile episodes. Oral mucositis (31.9\%) and upper respiratory tract $(29.7 \%)$ were the most common identifed infection foci (Table II).

Sixty eight $(50 \%)$ of febrile episodes were documented microbiologically. Bacterial documentation was made by hemoculture in $44(32.4 \%)$, by urine culture in $14(10.3 \%)$, by skin lesion culture in $10(7.4 \%)$ of febrile episodes. In $28(63.8 \%)$ of the 44 febrile episodes gram $(+)$ bacteria were isolated in hemoculture. Gram (-) bacteria were isolated in 9 episodes $(20.5 \%)$, and fungus were isolated in 7 episodes $(15.9 \%)$. The distribution of bacteria isolated from hemoculture were shown in Table III.

Skin lesion culture were made in 13 of febrile episodes. Microroganisms were isolated in 10 of these cultures. Microorganism isolated from skin lesion cultures and infection focus presented in Table IV.

In $14(10.3 \%)$ of febrile episodes microorganism were isolated by urine culture. E.coli (7), Enterococcus spp (2), Klebsiella pneumonia (2), Klebsilla oxytaca (1), Proteus mirabilis(1) and Methicillin-resistant Staphylococcus aureus (MRSA) (1) were isolated in urine culture. Pyuria was detected in 5 , and positivity of nitrite in 2 of them. Normal results was detected in 7 of urinalysis.

\section{Antibiotic treatments and outcomes}

Of the 136 febrile episodes, 96 (70.5\%) episodes improved with first line therapy, while modification of first line antibiotic therapy was required in 38 (27.9\%) episodes as second and third line therapy. Twenty-three episodes were improved with second line therapy while 15 episodes were improved third line therapy.

As first line treatment, 73 (75\%) children received cephalosphorins with amikacin. Ceftazidime+amikacin, cefepim + amikacin, cefaperazon-sulbactam + amikacin were given in $56(76.7 \%), 9(12.3 \%), 8$ (11\%) of febrile episodes, respectively. Ten $(10 \%)$ children received carbapenem. Fifteen (15\%) children received cephalosporins alone. Ceftazidime and cefepime were given in $9(60 \%)$ and $6(40 \%)$ of febrile episodes, respectively. Two child died while under the first line therapy (Table V).

Second line therapy was used in 23 of febrile episodes. Glycopeptide (teicoplanin) agent combination with ceftazidime +amikacin in 9 ( 1 child died), combination with cefepime+amikacin in 3 , combination with carbapenem in 11 ( 2 children died) of febrile episodes (Table VI).

Third line therapy was used in 15 of febrile episodes. Antifungal agent (amphotericin B) combination with ceftazidime+amikacin in 7 ( 1 child died) and combination with carbapenem in 8 (4 children died) of febrile episodes (Table VI). In this study, antibiotic treatment outcomes in overall treatment

Table III. The Distribution of Bacteria Isolated From Hemoculture.

\begin{tabular}{lccccc}
\hline Gram (+) bacteria & $\mathrm{n}$ & $\%$ & Gram (-) bacteria & $\mathrm{n}$ & $\%$ \\
\hline MSSA & 9 & 20.5 & G (-) agents & 3 & 6.8 \\
Corynebacteria spp. & 5 & 11.4 & Enterobacter spp. & 2 & 4.5 \\
Streptococcus spp. & 5 & 11.4 & P. aeruginosa & 1 & 2.3 \\
Enterococcus spp. & 4 & 9.1 & S. maltophila & 1 & 2.3 \\
MRSA & 2 & 4.5 & Enterobacteraerogenes & 1 & 2.3 \\
S. aureus & 1 & 2.3 & K. pneumoniae & 1 & 2.3 \\
S. pneumoniae & 1 & 2.3 & Total & 9 & 20.5 \\
MSSA and S. pneumoniae & 1 & 2.3 & & Fungus C. albicans & 6 \\
& & & Aspergillus & 13.6 \\
Total & 28 & 63.8 & & 2.3 \\
\hline
\end{tabular}

MSSA: Methicillin sensitive coagulase (-) staphylococcus aureus, MRSA: Methicillin resistant coagulase (-) staphylococcus aureus, S. aureus: Staphylococcus aureus, S. pneumoniae: Streptococcus pneumoniae, P. aeruginosa: Pseudomonas aeruginosa, K. pneumoniae : Klebsiella pneumoniae, C. albicans: Candida albicans. ${ }^{*}$ Not identified 
Table IV. Microorganism Isolated From Skin Lesions Cultures and Infection Focus.

\begin{tabular}{lc}
\hline Infection focus & Microorganisms (each patient) \\
\hline Catheter-related* & MSSA \\
Buccal abscess & MSSA Coli \\
Soft tissue & Enterobacter \\
& P. aeruginosa \\
Lip abscess & Enterobakter \\
Necrotic tissue & P. aeruginosa \\
& Acinetobacter \\
Maxillary sinus & Streptococcus spp. \\
Decubitus ulcer & C. albicans \\
\hline
\end{tabular}

*Catheter was removed, MSSA: Methicillin sensitive coagulase (-) staphylococcus aureus, P. aeruginosa: Pseudomonas aeruginosa, E. coli: Escherichia coli, C. albicans: Candida albicans.

were $96 / 136$ (70.5\%), 20/23 (86.9\%), 10/15 $(66.6 \%)$ of first line, second line and third line therapy, respectively. Treatment failed in $10(7.4 \%)$ of febrile neutropenic children. Two children were AML, eight children were ALL, two of them were relapse ALL. All ten deaths occurred during the febrile neutropenic episode. Three were from septic shock (two children in first line treatment, one child in second line treatment), three were from pneumonia and acute respiratory distress syndrome (two children in second line treatment, one child in third line treatment), three were from fungal sepsis and multiple organ dysfunction (all in third line treatment), one was from massive pulmonary hemorrhage (in third line treatment). Types of antibiotic treatment and outcomes were described as shown in Tables $\mathrm{V}$ and VI.

\section{Discussion}

Febrile neutropenia is a common complication associated with cancer and its treatment. Infections remain a major cause of morbidity in children with cancer, although mortality from infectious complications has diminished significantly 12,13 . Bacteria are the major causes of initial infection at early phase of febril neutropenia. Pathogens have evolved over time. Today gram-positive bacteria are the predominant cause of infections in granulocytopenic cancer patients Coagulase (-) staphylococci, Staphylococcus aureus, Streptococcus viridans and Enterococcus are the most common gram $(+)$ pathogens ${ }^{4}$.

Many reports from Turkey and other countries found different information related to isolated pathogens ratio with febrile neutropenia. Güneş

Table V. First Line Antibiotic Treatment and Outcomes

\begin{tabular}{|c|c|c|c|c|}
\hline \multirow[t]{2}{*}{ Antibiotic } & \multicolumn{2}{|c|}{$\begin{array}{l}\text { First line } \\
\text { treatment }\end{array}$} & \multicolumn{2}{|c|}{ Treatment outcome } \\
\hline & & $\mathrm{n}$ & $\mathrm{n}$ & $\%$ \\
\hline Ceftazidime & (9) & 9 & 9 & 100 \\
\hline Cefepime & (6) & 6 & 6 & 100 \\
\hline Ceftazidime + amikacin & $(72)$ & 56 & 54 & 96.4 \\
\hline Cefepime + amikacin & $(12)$ & 9 & 9 & 100 \\
\hline Cefaperazon-sulbactam + amikacin & (8) & 8 & 8 & 100 \\
\hline Carbapenem & $(29)$ & 10 & 10 & 100 \\
\hline Total & 136 & 98 & 96 & 70.5 \\
\hline
\end{tabular}


Table VI. Second and Third Line Antibiotic Treatment and Outcomes.

\begin{tabular}{lccc}
\hline $\begin{array}{l}\text { Second and third line } \\
\text { treatment }\end{array}$ & \multicolumn{2}{c}{ Treatment outcome } \\
& & $\mathrm{n}$ & $\%$ \\
\hline Ceftazidime+amikacin+teicoplanin & $(9)$ & 8 & 88.8 \\
Ceftazidime+amikacin+teicoplanin+amphotericin B & $(7)$ & 6 & 85.7 \\
Cefepime+amikacin+teicoplanin & $(3)$ & 3 & 100 \\
Carbapenem+teicoplanin & $(11)$ & 9 & 81.8 \\
Carbapenem+teicoplanin+amphotericin B & $(8)$ & 4 & 50 \\
Total & 38 & 30 & 78.9 \\
\hline
\end{tabular}

et al. ${ }^{11}$, Hamidi et al. ${ }^{14}$, Akan ${ }^{15}$, Sanboonrat et al. ${ }^{16}$ had all found gram (-) bacteria in about $85 \%, 73 \%, 56,8 \%, 50 \%$ respectively. Also Jeddi et al. ${ }^{17}$ found that gram (-) bacteria are predominant. Conversely, Düzova et al. ${ }^{18}$ $67 \%$, Kobayashi et al. ${ }^{19} 61 \%$, Paganini et al. ${ }^{20} 47 \%$ reported positive hemocultures for gram $(+)$ bacteria . Also Oguz et al. ${ }^{21}$ showed that gram $(+)$ bacteria are more frequently causative agents. In the present study the most commonly isolated agents were gram $(+)$ bacteria (63.8\%). Among the gram positives Methicillin-sensitive Staphylococcus aureus (MSSA) were the predominant pathogens $(20.5 \%)$ of febrile episodes (Table III).

In our study, we found the most common infection site was oral cavitiy and catheter entry site infections of which documented gram (+) bacteria by hemoculture. These results may be related to inadequate care and hygienic problems of our patients. According to the literature, such things as growing use of indwelling venous catheters and oral mucositis are risk factors for gram (+) infections in febrile neutropenic patients ${ }^{22,23}$. Our data also supported these investigations.

Several studies have reported that $24 \%$ to $55 \%$ of febrile episodes are fever of unknown origin 24,25. International Antimicrobial Therapy Cooperative Group-European Organization for Research and Treatment of Cancer (IATCGEORTC) have reported microbiological documentation in about $27 \%$ of the febrile patients $^{26}$. In our study, $68(50 \%)$ of febrile episodes were microbiologically documented which causes infection in neutropenic children. About 44 (32.4\%) of these episodes were associated with bacteremia. We were able to find that microbiologically documentation in this study may be associated with several factor, such as, their parents have low levels education, majority of parents could not make the measurement of fever and not admitted the hospital early time and our patients do not receive of antibacterial prophylaxis.

In our study $47(35 \%)$ of febrile episodes were clinically documented infections. The findings about source of infection seemed to be various. Some studies reported that most common site was respiratory $\operatorname{tract}^{27,28}$. Güneş et al. ${ }^{10}$ and Saanboonrat et al. ${ }^{16}$ found that the most common infection source was oral cavity. Oral mucositis and respiraory tract infections have similar proportions as the most frequent foci of infection were identified in our study (Table II).

With improved treatment and better survival from bacterial infections in febrile neutropenic patients, prevention and treatment of fungal infections have assumed greater importance, especially in patients with prolonged neutropenia. These infections tend to occur as secondary infections, rarely being identified at the onset of a febrile episode. Most fungal infections in children with cancer are caused by $C$. albicans accounting for most isolates. In recent years, an increase in prevalance of other Candida species such as C. glabrata, and C. crusei have become more common. However, C. albicans are still more frequent in many institutions ${ }^{29}$. In our study the incidence of microbiologically proven fungal infections were found in $15.9 \%$, although most isolated fungal agents were $C$. albicans.

In our study, the response rate was comparable to those of other beta-lactam-aminoglycoside regimens tested in such a pediatric population. In a prospective non-comparative open study of piperacillin plus gentamicin for the treatment 
of 239 febrile episodes in neutropenic children, Fleischhack et al. ${ }^{30}$ reported an overall response rate of $55.2 \%$. In a prospective, open-labeled, single-center study of single-daily dose of ceftriaxone plus amikacin for the treatment of 191 febrile episodes in neutropenic children, Ariffin et al. 31 reported an overall response rate of $55.5 \%$.

In our study, an overall response rate of $70.5 \%$ was achieved by the first-line treatment. These results suggested that ceftazidim plus amikacin therapy is effective in our neutropenic patients.

In conclusion, we suggest that complete physical examination which skin, mucous membranes, and sinuses should be done. Recommended initial treatment should be considered as guidelines, but alterations could be based on the predominant organisms isolated from patient population of each hospital. In this study we report the frequency of isolated microroganisms and infection site in our hematology clinic. Our study to was the first study to evaluate febrile episodes in neutropenic children in Southeast Anatolia.

\section{REFERENCES}

1. Hurtado IC, Sánchez DP, Espinal DA, Garcés C. Clinical and laboratory evolution of the febrile neutropenia episodes in pediatric patients hospitalized in a Colombian hospital in 2007-2009. Rev Chilena Infectol 2012; 29: 672-676.

2. Paul M, Yahav D, Fraser A, Leibovici L. Empirical antibiotic monotherapy for febrile neutropenia: systematic review and meta-analysis of randomized controlled trials. J Antimicrob Chemother 2006; 57: 176-189.

3. Laoprasopwattana K, Pruekprasert P, Laosombat V, Wongchanchailert M. Clinical outcome of febrile neutropenia in children with cancer using ceftazidime and aminoglycosides. Pediatric Hematol Oncol 2007; 24: $595-606$

4. Zinner SH. Changing epidemiology of infections in patients with neutropenia and cancer: emphasis on gram-positive and resistant bacteria. Clin Infect Dis 1999; 29: 490-494.

5. Hann I, Viscoli C, Paesmans M, Gaya H, Glauser M. A comparison of outcome from febrile neutropenic episodes in children compared with adults: results from four EORTC studies. International Antimicrobial Therapy Cooperative Grout (IATCG) of the European Organization for Research and Treatment for Cancer (EORTC). Br J Haematol 1997; 99: 580-588.

6. Gabay M, Tanzı M. Guidelines for the Managament of Febrile Neutropenia. Clinical Oncology News Special Edition 2010; 1: 115-122.
7. Jin J, Lee YM, Ding Y, et al. Prospective audit of febril neutropenia management at a Tertiary University hospital in Singapore. Ann Acad Med Singapore 2010; 39: $453-459$.

8. Paul M, Gafter-Gvili A, Leibovici L, et al. The epidemiology of bacteremia with febrile neutropenia: experience from a single center, 1988-2004. Isr Med Assoc J 2007; 9: 424-429.

9. Klaassen IL, de Haas V, van Wijk JA, Kaspers GJ, Bijlsma M, Bökenkamp A. Pyuria is absent during urinary tract infections in neutropenic patients. Pediatr Blood Cancer 2011; 56: 868-870.

10. Hakim H, Flynn PM, Knapp KM, Srivastava DK, Gaur A. Etiology and Clinical Course of Febrile Neutropenia in Children with Cancer. Pediatr Hematol Oncol 2009; 31: 623-629.

11. Güneş D, Mutafoğlu K, Çetinkaya H, Arslan H, Çakır $\mathrm{D}$, Olgun N. Febrile neutropenic episodes in children with lymphoma and malignant solid tumors. J Pediatr Inf 2010; 4: 1-8.

12. Viscoli C, Varnier O, Machetti M. Infections in patients with febrile neutropenia: epidemiology, microbiology, and risk stratification. Clin Infect Dis 2005; 40(Suppl 4): $240-245$.

13. Santolaya ME, Alvarez AM, Avilés CL, et al. Admission clinical and laboratory factors associated with death in children with cancer during a febrile neutropenic episode. Pediatr Infect Dis J 2007; 26: 794-798.

14. Hamidi AA, Başaran S, Çağatay AA, et al. Organisms isolated from blood cultures, their antimicrobial susceptibilities and patient characteristics in patients with febrile neutropenia. Klimik Journal 2009; 22: 88-91.

15. Akan ÖA. Microorganism isolated a from blood cultures of febrile neutropenic patients in İbn-i Sina Hospital. Turk J Haematol 2003; 20: 227-231.

16. Sanboonrat P, Chainansamit S, Sriraska K. Febrile neutropenia in children with acute leukemia. Khon Kaen Med J 2009; 33: 2-8.

17. Jeddi R, Achour M, Amor RB, et al. Factors associated with severe sepsis: prospective study of 94 neutropenic febrile episodes. Hematology 2010; 15: 28-32.

18. Düzova A, Kutluk T, Kanra G, et al. Monotherapy with meropenem versus combination therapy with piperacilin plus amikacin as empiric therapy for neutropenic fever in children with lymphoma and solid tumors. Turk J Pediatr 2001; 43: 105-109.

19. Kobayashi S, Ito M, Sano H, et al. Clinical analysis of combination therapy for febrile neutropenic patients in childhood cancer. Pediatr Int 2013; 55: 65-71.

20. Paganini H, Bologna R, Debbeq R, et al. Fever and neutropenia in children with cancer in one pediatric hospital in Argentina. Pediatr Hematol Oncol 1998; 15: 405-413.

21. Oguz A, Karadeniz C, Citak EC, Cil V. Eldes N. Experience with cefepime versus meropenem as empiric monotherapy for neutropenia and fever in pediatric patients with solid tumors. Pediatr Hematol Oncol 2006; 23: 245-253. 
22. Viscoli C, Van der Auwera P, Meunier F. Gram-positive infections in granulocytopenic patients: an important issue? J Antimicrob Chemother 1988;21( Suppl C): 149-156.

23. Meckler C, Lindemulder S. Fever and neutropenia in pediatric patients with cancer. Emerg Med Clin N Am 2009; 27: 525-544.

24. Aparicio J, Oltra A, Llorca C, et al. Randomised comparison of ceftazidime and imipenem as initial monotherapy for febrile episodes in neutropenic cancer patients. Eur J Cancer 1996; 32: 1739-1743.

25. Fleischhack G, Harttmann C, Simon A, et al. Mreopenem versus ceftazidime as empirical monotherapy in febril neutropenia of paediatric patients with cancer. J Antimicrob Chemother 2001; 47: 841-853.

26. Cometta A, Calandra T, Gaya H. et al. Monotherapy with meropenem versus combination therapy with ceftazidime plus amikacin as empiric therapy for fever in granulocytopenic patients with cancer. The International Antimicrobial Therapy Cooperative Group of the European Organization for Research and Treatment of Cancer and the Gruppo Italiono Malattie Ematologiche Maligne dell'Adulto Infection Program. Antimicrob Agents Chemother 1996; 40: 1108-1115.
27. Lai HP, Hsueh PR, Chen YC, et al. Bacteremia in hematological and oncological children with febrile neutropenia: experience in a tertiary medical center in Taiwan. J Microbiol Immunol Infect 2003; 36: 197-202.

28. Paganini H, Gomez A, Ruvinsky S, et al. Outpatient, sequential, parenteral-oral antibiotic therapy for lower risk febrile neutropenia in children with malignant disease A single-center, randomized, controlled trial in Argentina. Cancer 2003; 97: 1775-1780.

29. Hautala T, Ikaheimo I, Husu H. et al. A cluster of Candida krusei infections in a haematological unit. BMC Infectious Diseases 2007; 97: 1-8.

30. Fleischhack G, Schmidt-Niemann M, Wulff B, et al Piperacillin, beta-lactam inhibitor plus gentamicin as empirical therapy of a sequential regimen in febrile neutropenia of pediatric cancer patients. Support Care Cancer 2001; 9: 72-79.

31. Ariffin H, Arasu A, Mahfuzah M, Ariffin WA, Chan LL, Lin HP. Single-daily ceftriaxone plus amikacin versus thrice-daily ceftazidime plus amikacin as empirical treatment of febrile neutropenia in children with cancer. J Paediatr Child Health 2001; 37: 38-43. 